\section{Study of transforming growth factor beta 1 gene +869T/C polymorphism in Egyptian rheumatoid arthritis patients and its relation to disease activity}

\author{
Asmaa S. Hassan ${ }^{1}$, Abeer M. Abdul-Mohymen ${ }^{1}$, \\ Laila A. Ahmed ${ }^{2}$, Nora Seliem ${ }^{3}$, Marwa M. R. \\ Hassan $^{4}$, Hanan F. Ibrahim ${ }^{5}$, Mona G. Al Anan ${ }^{6}$
}

${ }^{1}$ Clinical Pathology Department, Faculty of Medicine for Girls, Al-Azhar University, Cairo, Egypt.

${ }^{2}$ Internal Medicine Department, Faculty of Medicine for Girls, Al-Azhar University, Cairo, Egypt.

${ }^{3}$ Biochemistry Department, Faculty of Medicine for Girls, AlAzhar University, Cairo, Egypt.

${ }^{4}$ Community Medicine Department, Faculty of Medicine for Girls, Al-Azhar University, Cairo, Egypt.
The Egyptian Journal of Immunology Volume 29 (1), 2022: 19-28. www.Ejimmunology.org
${ }^{5}$ Microbiology and Immunology Department, Faculty of Medicine for Girls, Al-Azhar University, Cairo, Egypt.

${ }^{6}$ Physiology Department, Faculty of Medicine for Girls, Al-Azhar University, Cairo, Egypt.

Corresponding author: Asmaa S. Hassan, Clinical Pathology Department, Faculty of Medicine for Girls, Al-Azhar University, Cairo, Egypt.

Email: asmsobhy@gmail.com.

\begin{abstract}
This study intended to explore the relationship between the +869T/C polymorphism of the transforming growth factor- $\beta 1$ (TGF- $\beta 1$ ) gene and rheumatoid arthritis (RA) predisposition and activity in Egyptian patients. The study involved 30 patients suffering from RA and 30 apparently healthy participants as the control group. The +869 T/C polymorphism of the TGF- $\beta 1$ gene was determined by the polymerase chain reaction-restriction fragment length polymorphism (PCR-RFLP) process. The TGF- $\beta 1+869 \mathrm{CT}$ genotype and $\mathrm{CT}+\mathrm{TT}$ genotypes in RA patients showed a significant increase than the control group (OR=3.782 and 3.824, $\mathrm{Cl}=1.046-13.680$ and $1.150-12.713, P=0.043$ and 0.029 , respectively). T allele showed a significant increase in patients than in controls (OR= 2.104, $\mathrm{Cl}$ 1.015- 4.361, $P=0.046)$. The TGF- $\beta 1+869 \mathrm{CT}+\mathrm{TT}$ genotypes were accompanied by higher DAS-28 scores which express higher disease activity, and increased levels of RF, Anti-CCP, ESR, and CRP. In conclusion, the TGF- $\beta 1+869 \mathrm{~T} / \mathrm{C}$ gene polymorphism may be accompanied by an increased predisposition to RA and with its severity in Egyptian RA patients.
\end{abstract}

Keywords: TGF- $\beta 1,+869 \mathrm{~T} / \mathrm{C}$, Polymorphism, Rheumatoid Arthritis

Date received: 23 October 2021; accepted: 22 December 2021

\section{Introduction}

Rheumatoid arthritis (RA) is a multi-system illness of autoimmunity with polyarthritis and joints damage. ${ }^{1}$ It affects around $1 \%$ of the worldwide population and about $0.2-0.3 \%$ in Egyptian population causing significant illness, mortality, and reduction of the quality of life. ${ }^{2}$ The etiology of the disease is still not clear, but it may be a result of a variety of hereditary and 
ecological agents which lead to abnormally increased synovial cells proliferation. ${ }^{3}$

The pathophysiology is mediated by several immune cells for example $T$ and $B$ lymphocytes, dendritic cells, and osteoclasts that infiltrate joints, destruct cartilages, and erode bones. ${ }^{4}$ This cellular infiltration and activation of these inflammatory cells release several inflammatory cytokines. Among the different cytokines, the transforming growth factor- $\beta 1$ (TGF- $\beta 1$ ) occupies a vital place in the pathogenesis. ${ }^{5}$ It is one of the large TGF- $\beta$ cytokines that include different regulatory cytokines. ${ }^{6}$

The TGF- $\beta$ behaves according to the present state. It is proven to be a profibrotic and proinflammatory cytokine, recruiting neutrophil, $T$ lymphocytes and other inflammatory cells to the site of joint inflammation, with synovial proliferation and causing bone resorption, angiogenesis, and production of other proinflammatory cytokines as TNF- $\alpha$ and IL-1. On the other hand, it is a well-known immune-regulatory cytokine inhibiting lymphocyte proliferation and suppresses the secretion of super oxides from macrophages. $^{7}$

Rheumatoid arthritis is associated with higher serum levels of TGF- $\beta 1 .^{8}$ About 110 genetic factors with increased susceptibility to RA was identified. These factors are associated with only small percent of heritability of RA patients. This fact increases the challenge in identifying other predisposing genetic factors. ${ }^{9}$

The gene of the TGF- $\beta 1$ is located on 19q13. $A$ variety of genetic polymorphisms has been reported in it. ${ }^{8}$ The TGF- $\beta 1$ gene +869T/C polymorphism ( $r$ 1800470) is associated with higher serum levels of TGF- $\beta 1{ }^{10}$

We intended to study the prevalence of TGF$\beta 1$ gene +869T/C polymorphism in Egyptian patients with RA compared to Egyptian apparently healthy controls and its relation to the activity of RA.

\section{Subjects and Methods}

\section{Study design}

This study was an observational analytical case control study. Sample size was calculated by using Power and Sample size program software
(PS). We planned the study of matched sets of cases and controls with 1 matched control per case. We expected the true odds ratio for rheumatoid arthritis in exposed subjects relative to unexposed subjects is 9; so, we needed to study 30 case patients with 1 matched control per case to be able to reject the null hypothesis that this odds ratio equals 1 with probability (power) 0.8. The Type I error probability associated with this test of this null hypothesis was 0.05 .

Patients were enrolled from the out-patient clinic and the in-patient Rheumatology Department in the Internal Medicine Department, Al-Zahraa University hospital, Faculty of Medicine for Girls, Al-Azhar University, Cairo, Egypt, between November 2020 and January 2021 and 30 control participants with corresponding age and sex. Patients included 18 females and 12 males, with ages, ranging from 23 to 58 years.

The study protocol was reviewed and approved by the Research Ethics Committee of Faculty of Medicine for Girls, Al-Azhar University (Approval No: 202011502). A written informed consent was taken from each participant.

Inclusion criteria included the American College of Rheumatology (ACR) classification criteria 2010 /European League against Rheumatism (EULAR) criteria for the diagnosis of RA. ${ }^{11}$

Exclusion criteria include other autoimmune diseases, chronic liver disease, primary renal disease, diabetes mellitus, malignant diseases, and pregnant or lactating females.

\section{Methods}

Full history was taken, and physical examination was done for all study members. The activity of RA was measured with the disease activity score (DAS-28). ${ }^{12}$

We had withdrawn four $\mathrm{ml}$ of venous blood from each participant and distributed them into two parts; $2 \mathrm{ml}$ were evacuated in an EDTA tube; one $\mathrm{ml}$ for ESR measurement and the residual one $\mathrm{ml}$ was stored at $-80^{\circ} \mathrm{C}$ for RFLPPCR. The remaining $2 \mathrm{ml}$ were evacuated in a plain tube, to separate serum which was used 
for C-Reactive protein (CRP), Rheumatoid factor (RF), and anti-cyclic citrullinated peptides (antiCCP).

The CRP and RF were measured by turbidimetric method (BioSystems, lot 19420 and 16980, respectively). Anti-CCP was assessed by quantitative sandwich enzyme-linked immunoassay (ELISA) (QUANTA Lite CCP3 lgG, lot 028509, reader; A1851 Das, Italy, and washer; 16041412 BioTek, USA), according to manufacturer's guidelines.

\section{DNA Extraction and Genotyping}

The DNA was extracted from the EDTA samples with a whole blood DNA purification Kit (Thermo Scientific Co. Ltd, lot 00459333). Purified DNA was kept at $-20^{\circ} \mathrm{C}$ for the determination of TGF- $\beta 1+869 \mathrm{~T} / \mathrm{C}$ genotype using PCR-RFLP. The upstream primer was 5'CGGCACCTCCCCCTGGCTCG-3' and the downstream one was 5'-CCTCCCCACCACACCAG-3' (New England BioLabs, USA). PCR cocktail consisted of $2.5 \mu \mathrm{L}$ Buffer (X10), $2.5 \mu \mathrm{L}$ of Mg2+ (25 mmol/L), $0.5 \mu \mathrm{L}$ of each primer, $2.0 \mu \mathrm{L}$ of DNA template (1 $\mu \mathrm{g} / \mu \mathrm{L}$ ), $1 \mathrm{U} / \mu \mathrm{L}$ for Taq enzyme (Cutsmart, B7204S, BioLabs, New England, USA) and double distilled water to $25 \mu \mathrm{L}$.

There was a pre-PCR holding stage at $60^{\circ} \mathrm{C}$ for $30 \mathrm{sec}$. and $10 \mathrm{~min}$ at $95^{\circ} \mathrm{C}, 40$ cycles (15 sec of denaturing at $95^{\circ} \mathrm{C}$, one min for annealing, and an extension at $60^{\circ} \mathrm{C}$ ), and a post-read stage at $60^{\circ} \mathrm{C}$ for $30 \mathrm{sec}$. Cycling conditions were 15 sec of denaturing at $95^{\circ} \mathrm{C}, 1 \mathrm{~min}$ of annealing, and extension at $60^{\circ} \mathrm{C}$. Cycling yields were processed with $1 \mathrm{U}$ restriction endonuclease Bsu36 I (R0524S, Lot 10080825, New England BioLabs, USA) for $2.5 \mathrm{~h}$ at $37^{\circ} \mathrm{C}$, then electrophoresis was done using agarose gel
(2.5\%) and Ethidium bromide (EB) stain. PCR products were digested with MspA1 I restriction enzyme for $4 \mathrm{~h}$ at 37oC. Enzyme-digested products were interpreted as follows: The $(244$ bp and $64 \mathrm{bp}$ ) products were considered $\mathrm{T}$ allele, while the (232 bp, $66 \mathrm{bp}$, and $12 \mathrm{bp}$ ) products were the $\mathrm{C}$ allele.

\section{Statistical analysis}

Results were reviewed, given codes, and entered in the Statistical Package for Social Science (IBM SPSS) version 23. Quantitative data were displayed as means, standard deviations, and ranges with parametric data and medians and inter-quartile ranges (IQR) with non-parametric data. Also, non-quantitative data were displayed as numbers and percentages. Comparison in non-quantitative data was done by Chi-square test and/or Fisher exact test when the predictable counts were < 5. Comparison in quantitative data with the parametric patterns was done by independent t-test, and with non-parametric patterns was done by Mann-Whitney test. The confidence interval was established as $95 \%$ and the accepted margin of error was established as $5 \%$. So, $p$-value was said to be significant if less than 0.05 .

\section{Results}

Demographic and clinical data of the study members are displayed in Tables 1 and 2 . The age of patients ranged from 23-58 years with a mean \pm SD of $38.6 \pm 7.95$. They were $60 \%$ females and $40 \%$ males. The control group had a corresponding age and sex. RF, anti-CCP, ESR, and CRP were significantly higher in RA patients than control members $(P<0.01)$, (Figure 1$)$.

Table 1. Patients demographic data and laboratory results.

\begin{tabular}{ccc} 
& & Patients group \\
Age (years) & Mean \pm SD & No. $=30$ \\
\hline \multirow{2}{*}{ Sex } & Range & $38.60 \pm 7.95$ \\
& Female & $23-58$ \\
\hline \multirow{2}{*}{ DAS-28 score } & Male & $18(60 \%)$ \\
& Mean \pm SD & $12(40 \%)$ \\
\hline \multirow{2}{*}{ Range } & $4.47 \pm 0.52$ \\
\end{tabular}


Table 1. Continued.

\begin{tabular}{|c|c|c|}
\hline & & Patients group \\
\hline & & No. $=30$ \\
\hline \multirow{2}{*}{$\mathrm{RF}(\mathrm{IU} / \mathrm{mL})$} & Mean \pm SD & $53.53 \pm 3.00$ \\
\hline & Range & $49-60$ \\
\hline \multirow{2}{*}{ Anti-CCP (U/ml) } & Median (IQR) & $119.4(83.4-153.3)$ \\
\hline & Range & $35.4-210$ \\
\hline \multirow{2}{*}{$\mathrm{ESR}(\mathrm{mm} / \mathrm{h})$} & Median (IQR) & $46.5(35-55)$ \\
\hline & Range & $15-62$ \\
\hline \multirow{2}{*}{ CRP (mg/L) } & Median (IQR) & $13(7-15)$ \\
\hline & Range & $3-20$ \\
\hline \multirow{6}{*}{ TGF- $\beta 1+869 T / C$} & $\mathrm{CC}$ & $5(16.7 \%)$ \\
\hline & $\mathrm{CT}$ & $16(53.3 \%)$ \\
\hline & $\mathrm{TT}$ & $9(30.0 \%)$ \\
\hline & $\mathrm{CT}+\mathrm{TT}$ & $25(83.3 \%)$ \\
\hline & C allele & $26(43.3 \%)$ \\
\hline & Tallele & $34(56.7 \%)$ \\
\hline
\end{tabular}

Abbreviations: DAS, disease activity score; RF, rheumatoid factor; CCP: cyclic citrullinated peptide; ESR, erythrocyte sedimentation rate; CRP, C-reactive protein; TGF, transforming growth factor.

Table 2. Comparison between demographic data and laboratory findings of both groups

\begin{tabular}{|c|c|c|c|c|}
\hline & & Control group & Patients group & \\
\hline & & No. $=30$ & No. $=30$ & \\
\hline \multirow{2}{*}{ Age (years) } & Mean \pm SD & $40.53 \pm 9.31$ & $38.60 \pm 7.95$ & \multirow{2}{*}{ NS } \\
\hline & Range & $27-55$ & $23-58$ & \\
\hline \multirow{2}{*}{ Sex } & Female & $16(53.3 \%)$ & $18(60 \%)$ & \multirow{2}{*}{ NS } \\
\hline & Male & $14(46.7 \%)$ & $12(40 \%)$ & \\
\hline \multirow{2}{*}{$\mathrm{RF}(\mathrm{IU} / \mathrm{mL})$} & Mean \pm SD & $7.20 \pm 1.94$ & $53.53 \pm 3.00$ & \multirow{2}{*}{0.000} \\
\hline & Range & $4-11$ & $49-60$ & \\
\hline \multirow{2}{*}{ Anti-CCP (U/ml) } & Median (IQR) & $8(6-10)$ & $119.4(83.4-153.3)$ & \multirow{2}{*}{0.000} \\
\hline & Range & $5-17$ & $35.4-210$ & \\
\hline \multirow{2}{*}{$\operatorname{ESR}(\mathrm{mm} / \mathrm{h})$} & Median (IQR) & $8(5-12)$ & $46.5(35-55)$ & \multirow{2}{*}{0.000} \\
\hline & Range & $4-20$ & $15-62$ & \\
\hline \multirow{2}{*}{$\mathrm{CRP}(\mathrm{mg} / \mathrm{L})$} & Median (IQR) & $4(3-5)$ & $13(7-15)$ & \multirow{2}{*}{0.000} \\
\hline & Range & $3-6$ & $3-20$ & \\
\hline
\end{tabular}

*: Chi-square test; $\bullet$ : Independent t-test; $\neq$ : Mann-Whitney test. $P>0.05$ is not significant (NS)

Abbreviations: DAS, disease activity score; RF, rheumatoid factor; CCP: cyclic citrullinated peptide; ESR, erythrocyte sedimentation rate; CRP, C-reactive protein. 


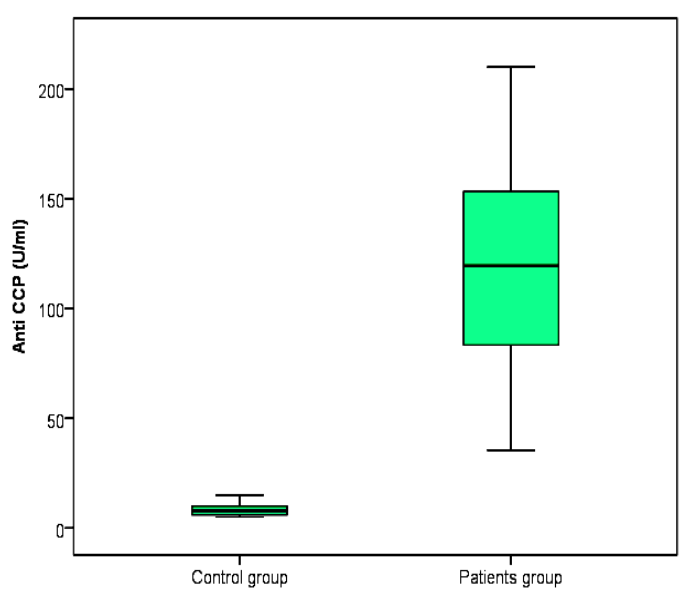

(A)

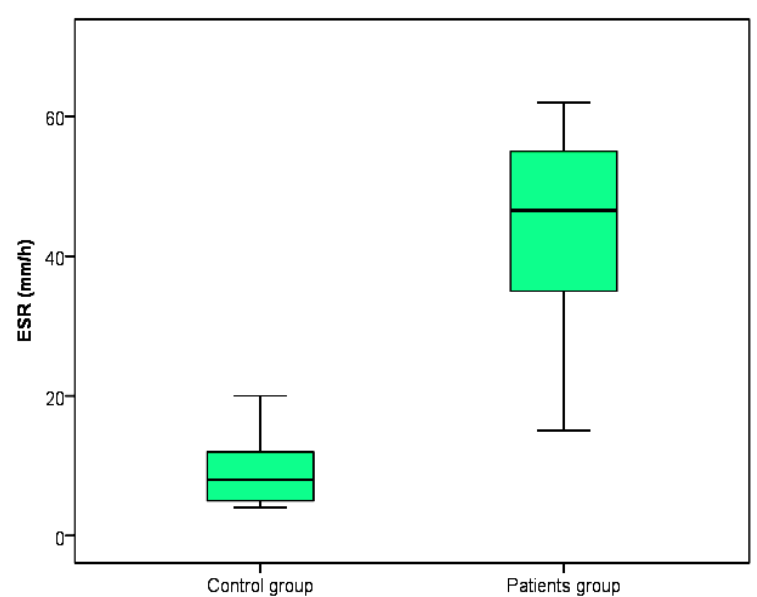

(B)

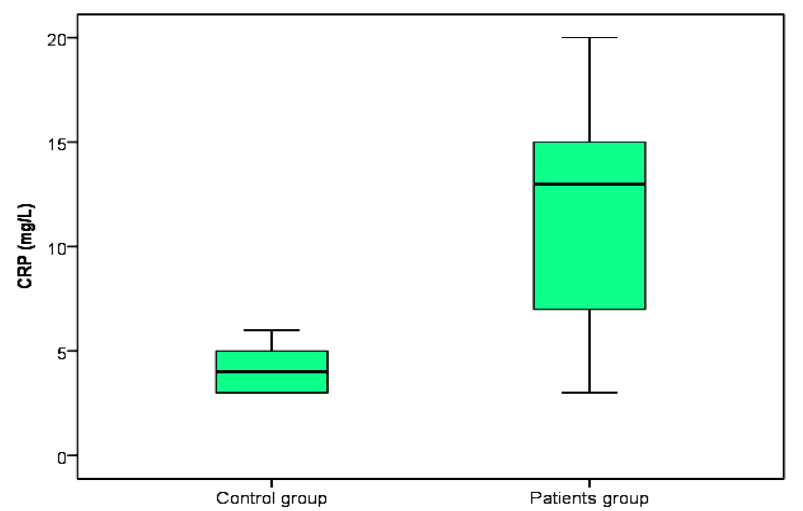

(C)

Figure 1. Comparison between patient and control groups regarding Anti-CCP (A), ESR (B), and CRP (C)

The genotype distributions of TGF- $\beta 1$ are illustrated in Table 3. The genotype frequency of $\mathrm{CT}$ showed a significant increase in RA patients than the control members $(\mathrm{OR}=3.782$, $\mathrm{Cl}=1.046-13.680, P=0.043)$. The prevalence of $\mathrm{CT}+\mathrm{TT}$ genotypes showed a significant increase in RA patients than the control members $(\mathrm{OR}=$ $3.824, \mathrm{Cl} 1.150-12.713, P=0.029)$, Table 3,
(Figure 2). The $T$ allele prevalence showed a significant increase in RA patients than the control members (OR= 2.104, $\mathrm{Cl} 1.015-4.361, P$ $=0.046)$. The CT+TT genotypes were accompanied by increased DAS-28 scores $(P=0.002), \mathrm{CRP}, \mathrm{ESR}$, anti-CCP, and RF $(P=0.001)$ (Table 4) (Figure 3).

Table 3. Prevalence of TGF- $\beta 1+869 \mathrm{~T} / \mathrm{C}$ genotypes in both groups.

\begin{tabular}{|c|c|c|c|c|}
\hline \multirow{2}{*}{ TGF- $\beta 1+869 T / C$} & Control group & Patients group & \multirow{2}{*}{$\begin{array}{c}\text { OR } \\
(\mathrm{Cl} \% \mathrm{Cl})\end{array}$} & \multirow{2}{*}{$P$-value } \\
\hline & No. $=30$ & No. $=30$ & & \\
\hline CC (wild genotype) & $13(43.3 \%)$ & $5(16.7 \%)$ & Ref. & - \\
\hline CT & $11(36.7 \%)$ & $16(53.3 \%)$ & $3.782(1.046$ to 13.680$)$ & 0.043 \\
\hline TT & $6(20.0 \%)$ & $9(30.0 \%)$ & 3.900 (0.906 to 16.789$)$ & NS \\
\hline
\end{tabular}


Table 3. Continue.

\begin{tabular}{|c|c|c|c|c|}
\hline \multirow{2}{*}{ TGF- $\beta 1+869 T / C$} & Control group & Patients group & \multirow{2}{*}{$\begin{array}{c}\text { OR } \\
(\mathrm{Cl} \% \mathrm{Cl})\end{array}$} & \multirow{2}{*}{$P$-value } \\
\hline & No. $=30$ & No. $=30$ & & \\
\hline $\mathrm{CC}$ & $13(43.3 \%)$ & $5(16.7 \%)$ & Ref. & - \\
\hline $\mathrm{CT}+\mathrm{TT}$ & $17(56.7 \%)$ & $25(83.3 \%)$ & $3.824(1.150$ to 12.713$)$ & 0.029 \\
\hline C allele & $37(61.7 \%)$ & $26(43.3 \%)$ & Ref. & - \\
\hline T allele & $23(38.3 \%)$ & $34(56.7 \%)$ & $2.104(1.015$ to 4.361$)$ & 0.046 \\
\hline
\end{tabular}

*: Chi-square test, OR: odds ratio, $\mathrm{Cl}$ : confidence interval. $P>0.05$ is not significant (NS). Abbreviations: TGF, transforming growth factor.

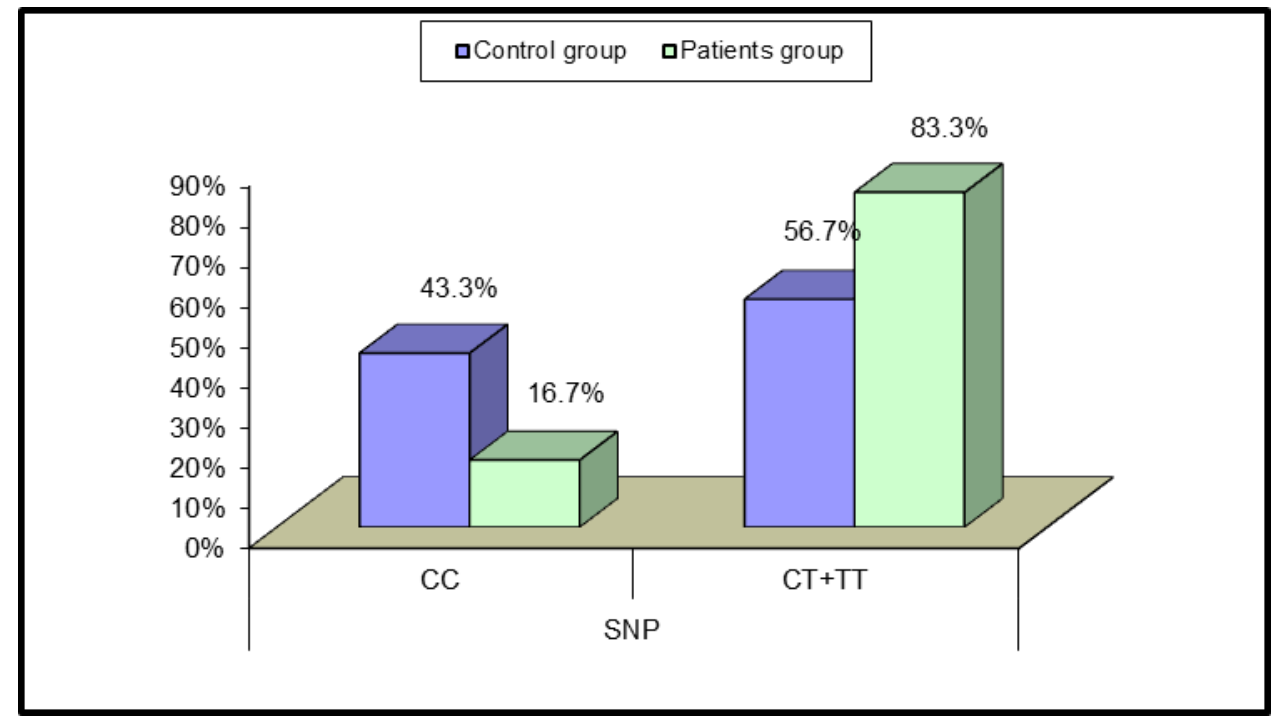

(A)

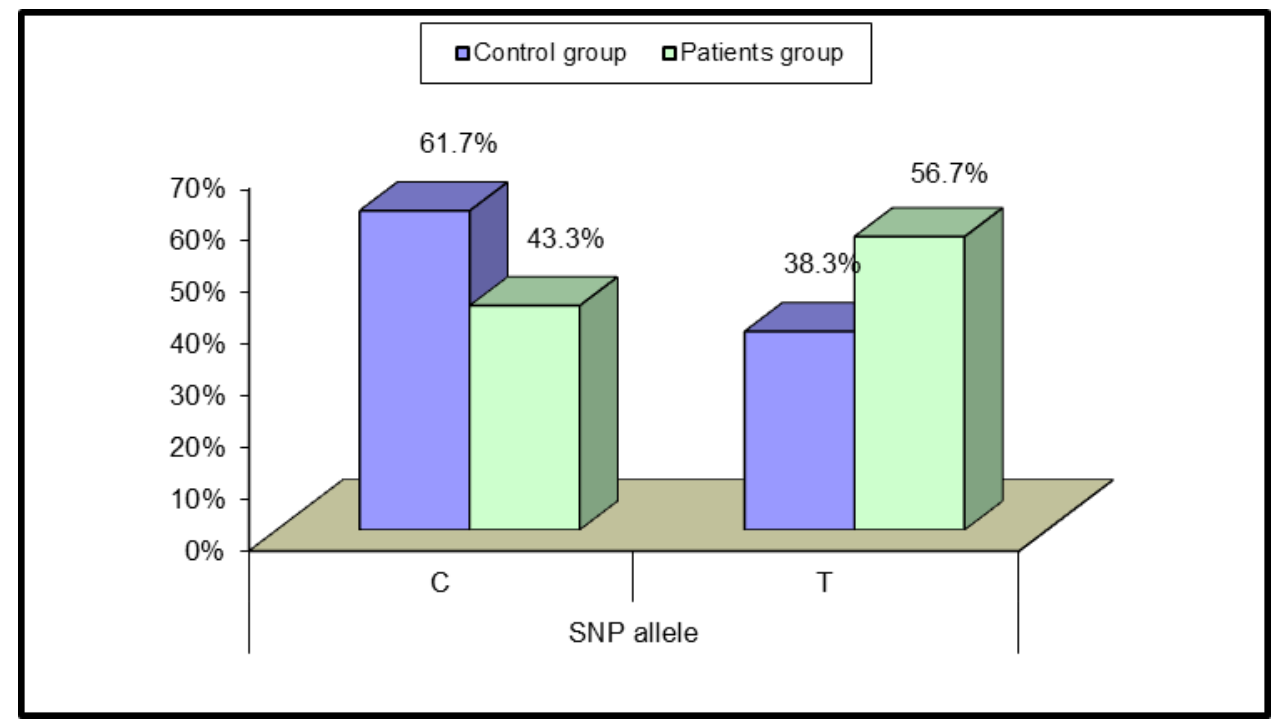

(B)

Figure 2. Comparison between patient and control groups regarding genotypes $C C$ and $C T+T T(A)$, and $C$ and $T(B)$. 
Table 4. Comparison between TGF B1 +869T/C genotypes regarding various clinical parameters in patients.

\begin{tabular}{|c|c|c|c|c|}
\hline & & $\mathrm{CC}$ & $\mathrm{CT}+\mathrm{TT}$ & \multirow{2}{*}{$P$-value } \\
\hline & & No. $=5$ & No. $=25$ & \\
\hline \multirow{2}{*}{ Age (years) } & Mean \pm SD & $37.40 \pm 8.96$ & $38.84 \pm 7.91$ & \multirow{2}{*}{ NS } \\
\hline & Range & $29-52$ & $23-58$ & \\
\hline \multirow{2}{*}{ Sex } & Female & $4(80.0 \%)$ & $22(88.0 \%)$ & \multirow{2}{*}{ NS } \\
\hline & Male & $1(20.0 \%)$ & $3(12.0 \%)$ & \\
\hline \multirow{2}{*}{ DAS-28 score } & Mean \pm SD & $3.84 \pm 0.44$ & $4.59 \pm 0.44$ & \multirow{2}{*}{0.002} \\
\hline & Range & $3.50-4.50$ & $3.4-5.2$ & \\
\hline \multirow{2}{*}{ RF (IU/mL) } & Mean \pm SD & $49.60 \pm 0.55$ & $54.32 \pm 2.64$ & \multirow{2}{*}{0.001} \\
\hline & Range & $49-50$ & $50-60$ & \\
\hline \multirow{2}{*}{ Anti-CCP (U/ml) } & Median (IQR) & $72(51.3-72.3)$ & $136(97.8-160)$ & \multirow{2}{*}{0.001} \\
\hline & Range & $35.4-79.3$ & $80-210$ & \\
\hline \multirow{2}{*}{$\mathrm{ESR}(\mathrm{mm} / \mathrm{h})$} & Median (IQR) & $21(17-24)$ & $48(40-55)$ & \multirow{2}{*}{0.000} \\
\hline & Range & $15-30$ & $35-62$ & \\
\hline \multirow[b]{2}{*}{ CRP (mg/L) } & Median (IQR) & $4(4-5)$ & $15(11-16)$ & \multirow[b]{2}{*}{0.001} \\
\hline & Range & $3-5$ & $5-20$ & \\
\hline
\end{tabular}

*: Chi-square test; $\bullet:$ Independent t-test; $\neq$ : Mann-Whitney test. $P>0.05$ is not significant (NS). Abbreviations: DAS, disease activity score; RF, rheumatoid factor; CCP: cyclic citrullinated peptide; ESR, erythrocyte sedimentation rate; CRP, C-reactive protein.
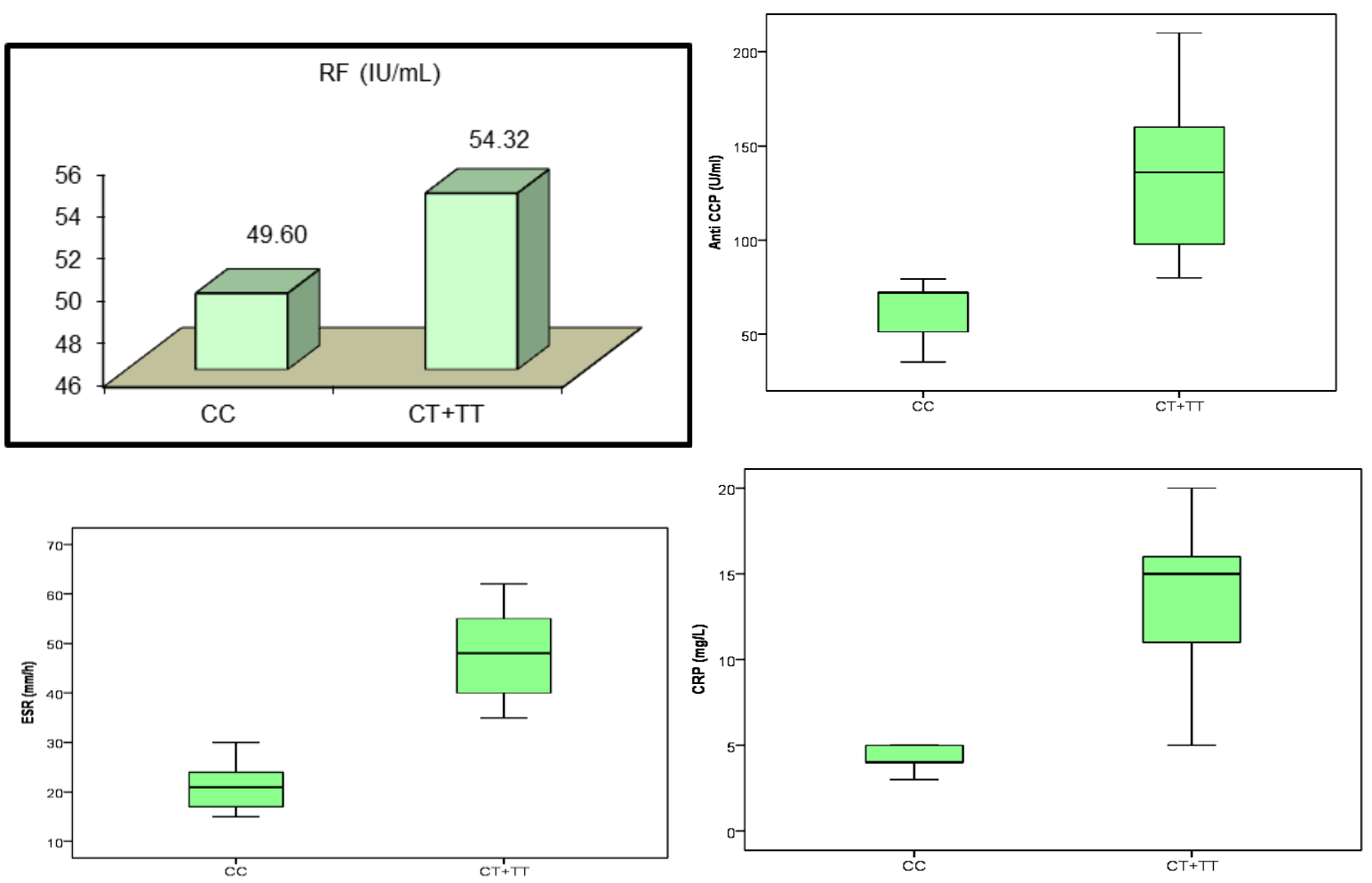

Figure 3. Correlation between genotypes and RF, Anti-CCP, ESR and CRP in patient group. 


\section{Discussion}

In the current work, we studied the distribution of TGF- $\beta 1$ gene +869T/C polymorphism among RA patients in Egypt and its correlation with disease severity. The $\mathrm{CC}, \mathrm{CT}$, and $\mathrm{TT}$ genotypes frequencies in RA patients were $16.7 \%, 53.3 \%$, and $30 \%$, respectively. These findings agree with those of studies by Said et al., $2014^{13}$ on Egyptian RA patients, Mattey et al., $2005^{14}$ on Northern European RA patients, and Sugiura et al., $2002^{15}$ on Japanese RA patients who found similar frequencies. However, Patel et al., $2020^{16}$ found that the frequencies of these genotypes in North Indian RA patients were $17.1 \%, 19.7 \%$, and $63.2 \%$, respectively. Also, Panoulas et al., $2009^{17}$ found that their frequencies in UK RA patients were $14.7 \%$, $44.6 \%$, and $40.8 \%$, respectively. The difference in these study findings may be explained by the association between race and genetic profile or by exposure to different environmental factors.

In this study, the $T$ allele prevalence was significantly increased in patient group than in the control group $(\mathrm{OR}=2.104, \mathrm{Cl} 1.015-4.361, P$ $=0.046)$. The frequencies of CT genotype and that of $\mathrm{CT}+\mathrm{TT}$ genotypes in RA patients were significantly increased than in the control participants $(\mathrm{OR}=3.782$ and $3.824, \mathrm{Cl}=1.046$ 13.680 and $1.150-12.713, \mathrm{P}=0.043$ and 0.029 respectively), while the $\mathrm{C}$ allele frequency $(16.7 \%)$ was decreased in patients than in the control groups (43.3\%). These results agree with those of the study by Patel et al., 2020 who found significantly increased prevalence of $T$ allele and both CT and TT genotypes in North Indian RA patients than in controls. ${ }^{16}$ Also, Zhou et al., $2014{ }^{18}$ found that the TT genotype in Chinese was accompanied by a higher susceptibility of $\mathrm{RA}(\mathrm{OR}=1.28, \mathrm{Cl}=1.02-1.60$, $P=0.03)$. These results were supported by data of a study of C-509T polymorphism of the same gene on UK female twins. ${ }^{19}$

Although Sugiura et al., $2002^{15}$ found a significantly increased prevalence of the T allele in Japanese RA patients, they found nonsignificant distribution alteration in genotypes between RA patients and normal controls. Also, Panoulas et al., 2009 found a non-significant alteration between RA patients and controls in the UK residents. ${ }^{17}$

The $T$ allele results in reduced TGF- $\beta 1$ expression, with a faster progression of RA and aggravation of inflammation due to the resultant alteration of the signaling peptide which alters various metabolic pathways. ${ }^{14}$

In our study, the CT+TT genotypes were correlated with higher DAS-28 scores $(p=0.002)$, CRP, ESR, anti-CCP, and RF $(p=0.001)$. This association suggests that the studied polymorphism is significantly linked with the activity of rheumatoid arthritis. These results agree with findings of the study by Patel et al., 2020 on North Indian RA patients. ${ }^{16}$ Also, Panoulas et al., $2009^{17}$ found a significant increase of anti-CCP antibodies in the $\Pi T$ genotype compared with the other two genotypes in UK RA patients. However, the latter group did not find a significant relation between genotypes and ESR, CRP, DAS-28, or RF. Similarly, Sugiura et al., $2002^{15}$ found no correlation between genotypes and osteoarthritis or joint replacement in Japanese RA patients. Also, Mattey et al., $2005^{14}$ found no correlation between genotypes and ESR or CRP in Northern European RA patients. Again, racial and environmental factors may explain these differences.

The present study had few limitations including its small sample size. We also tested a single polymorphism in the TGF $\beta 1$ gene, due to financial deficit. Studies of other polymorphisms in the same gene and other cytokines genes should be further investigated in the Egyptian population. The potential role of therapeutics affecting the TGF- $\beta 1$ may provide a focus of future clinical trials investigating their role as an adjuvant to treatment regimens.

In conclusion, this study demonstrated that the +869 T/C polymorphism of the TGF- $\beta 1$ gene may be accompanied by increased susceptibility to RA and with its increased severity in Egyptian RA patients. There is a strong probability that gaining the $T$ allele in this polymorphism increases susceptibility for the disease development and increases the disease activity. 


\section{Author Contributions}

ASH, AMA; performed the laboratory work. LAA; examined the patients and collect the patient samples. NS, MMRH, HFI, MGA; perform statistical analysis. All authors participated in writing and reviewing the paper.

\section{Declaration of Conflicting Interests}

The author(s) declared no potential conflicts of interest with respect to the research, authorship, and/or publication of this article.

\section{Funding}

The author(s) denies receipt of any financial support for the research, authorship, and/or publication of this article.

\section{Ethical approval}

The study protocol was reviewed and approved by the Research Ethics Committee of Faculty of Medicine for Girls, Al-Azhar University (Approval No: 202011502).

\section{Informed consent}

A written informed consent was taken from each participant.

\section{References}

1. Guo Q, Wang Y, Xu D, et al. (2018). Rheumatoid arthritis: pathological mechanisms and modern pharmacologic therapies. Bone Res. 6:15.

2. El Saman AM, Mohamed ER, Khalifa A, et al. (2020). Evaluation of Awareness, Knowledge and Attitudes regarding Common Rheumatic Diseases (Rheumatoid Arthritis and Systemic Lupus Erythematous) in Sohag Governorate. The Egyptian Journal of Community Medicine. 38(2): 25-36.

3. Scherer HU, Burmester THG. (2020). The etiology of rheumatoid arthritis. Journal of Autoimmunity. 110: 102400.

4. Yap HY, Tee SZ, Wong MM, et al. (2018). Pathogenic Role of Immune Cells in Rheumatoid Arthritis: Implications in Clinical Treatment and Biomarker Development. Cells. 7(10):161.

5. Wojdasiewicz $P$, Poniatowski $Ł A$, Szukiewicz D. (2014) The role of inflammatory and antiinflammatory cytokines in the pathogenesis of osteoarthritis. Mediators Inflamm. 561459.
6. Rao Y, Fang Y, Tan W, et al. (2020) Delivery of long non-coding RNA NEAT1 by peripheral blood mononuclear cells-derived exosomes promotes the occurrence of rheumatoid arthritis via the microRNA-23a/MDM2/SIRT6 axis. Front Cell Dev Biol. 8:551681.

7. Gonzalo-Gil E, Galindo-Izquierdo M. (2014). Role of transforming growth factor-beta (TGF) beta in the physiopathology of rheumatoid arthritis. Reumatol Clin. 10(3):174-9.

8. Muñoz-Valle JF, Torres-Carrillo NM, GuzmánGuzmán IP, et al. (2012). The functional class evaluated in rheumatoid arthritis is associated with soluble TGF- $\beta 1$ serum levels but not with G915C (Arg25Pro) TGF- $\beta 1$ polymorphism. Rheumatol Int. 32(2):367-72.

9. Onuora S. (2021). New insights into RA genetics from GWAS meta-analysis. Nat Rev Rheumatol. 17, 128.

10. Li X, Shen L, Tan H. (2014). Polymorphisms and plasma level of transforming growth factor-Beta 1 and risk for preeclampsia: a systematic review. PLoS One. 9(5): e97230.

11. Aletaha D, Neogi T, Silman AJ, et al. (2010). Rheumatoid arthritis classification criteria: an American college of rheumatology/European league against rheumatism collaborative initiative. Arthritis Rheum. 62(9):2569-2581.

12. Prevoo ML, van't Hof MA, Kuper HH, et al. (1995). Modified disease activity scores that include twentyeight-joint counts. Development and validation in a prospective longitudinal study of patients with rheumatoid arthritis. Arthritis Rheum. 38(1):44-8.

13. Said GA, Hussein Y, El-Sayed H, et al. (2014). Gene polymorphism of transforming growth factor beta-1 (TGF-B1) and its level in rheumatoid arthritis patients associated with osteoporosis disease. Z.U.M.J. 20(1):1-18.

14. Mattey DL, Nixon N, Dawes P T, et al. (2005). Association of polymorphism in the transforming growth factor B1 gene with disease outcome and mortality in rheumatoid arthritis. Ann Rheum Dis. 64:1190-1194.

15. Sugiura Y, Niimi T, Sato S, et al. (2002). Transforming growth factor beta1 gene polymorphism in rheumatoid arthritis. Ann Rheum Dis. 61(9): 826-828.

16.Patel SL, Prakash J, Gupta V. (2020). TGF- $\beta 1$ $+869 \mathrm{C} / \mathrm{T}$ polymorphism increases susceptibility to rheumatoid arthritis in North Indian population. Clin Rheumatol. 39(10):2881-2888.

17. Panoulas VF, Douglas KMJ, Smith JP, et al. (2009). Transforming growth factor- $\beta 1$ 869T/C, but not interleukin-6 -174G/C, polymorphism associates 
with hypertension in rheumatoid arthritis, Rheumatology. 48(2):113-118

18. Zhou TB, Zhao HL, Fang SL, et al. (2014). Association of transforming growth factor- $\beta 1$ T869C, G915C, and C509T gene polymorphisms with rheumatoid arthritis risk. J Recept Signal Transduct Res. 34:469-475.

19. Grainger DJ, Heathcote K, Chiano M, et al. (1999). Genetic control of the circulating concentration of transforming growth factor type beta1. Hum Mol Genet. 8:93-97. 